\title{
DYNAMIC MUSICSCAPES IN NORTHERN GREECE: A ROMA CASE STUDY
}

\author{
Christos Papakostas
}

School of Physical Education and Sport Science

National \& Kapodistrian University of Athens, Greece

e-mail: chpapak@phed.uoa.gr

\section{Dimitris Goulimaris}

Department of Physical Education and Sport

Democritus University of Thrace, Greece

e-mail:dgoulima@phyed.duth.gr

\author{
Maria Douma \\ MSc in Education Studies \\ University of Patras, Greece \\ e-mail:doumamaria@hotmail.com
}

\begin{abstract}
In recent years, there has been a considerable debate in social sciences concerning the relationship between place and culture, the dominant view being that this relationship is 'physical'. Groups have been identified as part of specific geographical spaces and their culture has been likewise considered as rooted in a particular territory. This theory is rather due to the phenomenon of nationalism, since part of its rhetoric is reinforced by substantiating the relationships among place, community, and culture. Lately, though, anthropologists have challenged the aforesaid essentialist approach. The concepts of culture and identity, disengaged from their correspondence with space, no longer constitute homogenous and static categories which define one group of people diachronically. This paper, based on the ethnographic example of the Roma (Gypsies) of Iraklia-Serres in Northern Greece, makes clear that, for the Roma, the term local (dopia) music is not monolithic, although it displays a high degree of relativity. In Roma professional logic, the concept of music is not constructed around final conclusions but is constituted by all kinds of practice, categorisation, and classification. What is enhanced in each case is the meaning of the music as an expression of place and identity. The Roma musicians, either as protagonists or as extras, represent their ethnic group and test the permeability of the boundaries (spatial, ethnic, symbolic), which are being continually repositioned in relation to the different reference points.
\end{abstract}

Keywords: ethnoscapes, identity, Gypsies, music, place, Roma 
If the zournas ${ }^{1}$-players are from Tzoumaya, there's nothing to worry about. This place produces the best instrument players, there's no doubt about it. The job will be done. (Kotas, personal communication, June 2001)

\section{MUSIC AND PLACE}

The main goal of this paper is to examine the relationship between music and the cultural identity of an ethnic group of people, as connected to the place they live in.

For many years, the dominant view has been that the relation between place and culture is 'physical'. Groups have been identified as part of specific geographical spaces, and their culture has been likewise considered as rooted in a particular territory. This approach is indicative of a taxonomic logic, which demands clear categories of cultures and cultural areas and is rather due to the phenomenon of nationalism, since part of its rhetoric is reinforced by substantiating the relation among place, community, and culture.

Lately though, anthropologists have challenged the aforesaid essentialist approach (Gupta \& Ferguson 1992; Olwig \& Hastrup 1997). New phenomena such as migration, diaspora communities, hybrid cultures and identities, the continuous circulation of materials and cultural goods or the development of new technologies have prompted re-examining the concept of 'culture/place' (Olwig \& Hastrup 1997: 3).

The concepts of culture and identity are disengaged from their correspondence with space and no longer constitute homogenous and static categories which define one group of people diachronically. Consequently, culture is perceived as a historical dynamic category which is in continual flux, being an object of negotiation of collective identities and heterogeneities (Nitsiakos 2006: 363).

The theoretical framework which initiated the present article is the theory of practice (Bourdieu 1977; Ortner 1984). According to this theory, music is formed by cultural practices 'through which a community manages its past and present, is reconstituted at a symbolic level and incorporates the elements of modern developments in its tradition, in a dynamic manner' (Nitsiakos 2006: 87). New ideas of place and identity as well as the relations among social groups, which are always relations of power, are incorporated in cultural practices and structure them. Practices are the ways and the fields through which these ideas 'are realized - that is, are understood and become real' (Cowan 1990: 16). This choice of theoretical framework helps us to overcome the dichotomy of structure/action and, consequently, to overcome the problem of substantiating the relationship between place and music. 
Music should not be perceived as a static cultural phenomenon, as a 'corpus' of stable and unaltered characteristics, but as a dynamic process 'historically determined and subjected to social and political manipulations and negotiations' (Nitsiakos 2006: 88). This perspective allows us to examine music beyond the view that it is identified with space, in other words, the view that music is rooted in a particular geographical territory.

Methodically, the paper is based on the results of systematic ethnographic fieldwork that took place between 2000 and 2002.

\section{THE ROMA IN/OF IRAKLIA}

Iraklia (formerly known as Tzoumaya) is a mixed community of semi-urban type $^{2}$ made up of individual ethnic groups. Today, the Vlachs, Roma (Gypsies), locals (dopioi), refugees, and a small number of Sarakatsani live together in Iraklia. This population mixture occurred after the end of the Balkan Wars and the Greeks' defeat in Asia Minor (1922). However, prior to these important historical milestones, Iraklia was inhabited by various Muslim populations and also the Muslim Roma. Since the mid-1970s, the semi-nomadic Tsinganoi also settled there. ${ }^{3}$

In general, the historical course of Iraklia is concurrent with the weakening of the Ottoman Empire, the constitution of Balkan nation-states (Mazower 2000), and their dispute over the geographical borders of Macedonia. Above all, in the case of Iraklia, this dispute resulted in significant spatial rearrangements caused by:

- Bulgarian and German occupation (1916-18);

- total destruction in 1916 and displacement of its inhabitants to Požarevac in Serbia;

- their return in 1918;

- rebuilding of the settlement in 1930 and its inclusion in the frontier zone of the newly-established Greek State.

The Roma are an inextricable part of the history of Iraklia, even though this is not recorded in the official textual sources (Aslanidis 1997; Kaftantzis 1973; Tzemailas 1973). The local elite, which mainly comes from the ranks of the Vlachs and is in charge of recording history, completely ignores the Roma and their role in the mixed community; any references to them are general and, mainly, in relation to music.

Nevertheless, the fact that the Roma are born in a mahala (neighbourhood ${ }^{4}$ ), which is a sub-space of the wider area of Iraklia, underlines their direct rela- 
tion with the particular space through ties of blood and land. They themselves consider this fact as proof of their localness. Furthermore, the space functions also as a geographical representation of the dipole 'we/others', since the mahala is opposed to the agora (marketplace), the space of the Vlachs. ${ }^{5}$ This observation is exceptionally important for the constitution of the Roma cultural identity, since they consider the mahala - and simultaneously Iraklia - as 'their place'.

\section{PROFESSIONAL MUSICIANS}

Vasilis Kaftantzis, an Iraklian of Vlach origin, in his book titled The History of Iraklia, and specifically in the chapter 'Intellectual and Artistic Activity', notes, inter alia:

The Tzoumayans were famed for their love of song and music. Indeed, it is noteworthy that most of the songs of its Vlachs are old folk klepht ${ }^{6}$ and love songs. Their lamentations are wonderful, too. But the Gyftoi ${ }^{7}$ of Tzoumaya, Christians, and Muslims, were also renowned for their musical prowess. Their music bands (made up of two shawms [zournades] - first and second - and a drum (daouli ${ }^{8}$ ), accompanied by one or, very often, two fiddles) were the only ones used in that period for weddings, patronal feasts, glendia ${ }^{9}$, and dances. One family predominantly of Christian Gyftoi, the Goras, with hereditary love of music and rare talent, produced instrument-players, zournatzides, such as Grigoris Goras, his son Vangelis and his grandson Grigoris, who became famous all over European Turkey. The Chitzios family also produced excellent instrument-players, the zournatzides Petros Chitzios, Kolias Chitzios, and his son Mitsios Chitzios, who had theoretical training and were able to play all the wind instruments. Another well-known professional musician, in great demand among the Turks and Christians, was the Tourkogyftos [Turk-Gypsy] Zorap, an outstanding fiddle player. (Kaftantzis 1973: 132-133)

The above excerpt is the sole potentially positive representation of the Roma in Kaftantzis's book. Thus, thanks to music, a whole group of people becomes 'visible' and gets out of the fringe of society. The skilfulness of the professional Roma musicians, Christians and Muslims, is the reason for the appearance of the Roma in the history of Iraklia. Still, there are some questions to be answered: To what extent is this professional occupation of the Roma their own choice and under what conditions was it formulated? Is it in fact a 'choice'?

Kaftantzis's reference to the 'hereditary love and true talent' of the Goras family is supported by a narrative that verges on myth: 
Once, a Turkish army pitched camp near Tzoumaya. Its commander had a horse trained to dance when it heard music. And so he invited the famed Goras (possibly Vangelis) ... who played best. (Kaftantzis 1973: 133)

During the course of fieldwork, several interviews and discussions were held with the zournatzis (shawm-player) Grigoris Goras, grandson of the 'old' legendary Grigoris Goras (son of Vangelis). Grigoris often returned to the subject of his grandfather and his musical ability, which in those years was acknowledged by all in Tzoumaya, both Christians and Muslims. Like Kaftantzis, Grigoris recounts vividly and dramatically the following folk legend:

And when he heard the bey [Goras, my grandfather play], he became jealous and he sent a ceta [group] of three men to behead him. They came to the house on their horses and, so the story goes, they said to him: 'Goras, come. We're taking you with us'. My grandfather understood the danger and said to my grandmother: 'Bring me the zournas'. At the time, the zournas was hanging on the wall, with its chains, with its things, just hanging. 'Fetch me the zournas from there'. My grandfather, with his zournas in his hand, was taken outside, to face those men on their horses, holding their swords, the 'scimitars', as we call them. My grandfather told them: 'Excuse me, but before you behead me, I'd like to play an Otur havaci [a table song]. Afterwards, you can do what you think fit'. My grandfather took his zournas and he began to play. While he was playing that very sweet melody, a nightingale perched on the mouthpiece of the zournas. Now, when the soldiers saw this, their swords fell from their hands and they said: 'Because we've sworn an oath to take a blood-stained sword to our bey, we'll cut off your little finger'. They indeed cut off his finger but even in pain, my grandfather kept playing. The song that he played, the 'Amus pehlivanas' as we call it, is very popular in Doxato, a town in our region, and is highly requested. ${ }^{10}$

The versions narrated by Grigoris and Kaftantzis, as representatives of the local elite, display remarkable elements of convergence or even coincidence. The myth is interesting not only to analyse morphologically, but also to read and interpret. If we agree with Barthes (1972) that 'myth is discourse', then what are the issues that this myth projects and negotiates? The element that is projected forcibly in all these versions of the myth is the Roma's given relation with music and their consequent ability to entertain, to amuse the 'other'. Concurrently, the myth also addresses the issue of the music's origin, since it identifies music with the Roma. Thus, it acquires the character of a myth of origin, a very important fact for the identity of the Roma, and is directly linked with the survival of the ethnic group. Generally speaking, the myth on the Roma's 
relation with music uses the past to serve contemporary or future objectives. Such intentions are revealed both through the myth and the historical events. Before the displacement of the Tzoumayans to Serbia, Christian and Muslim Roma played at feasts and ceremonies. In several cases, the cetas (bands) of musicians were created with the collaboration of Christian and Muslim musicians, so they were of mixed composition. The departure of the Muslim Roma ${ }^{11}$ left a professional vacuum, mainly in relation to music (Keil et al. 2002).

Apparently, professional opportunities for the Roma were usually found in those occupations which the others were less capable of undertaking or were reluctant to undertake (Okely 1983: 49). ${ }^{12}$ Thus, the Roma's involvement with music constituted a vital and attractive social space, which seemed logical and, moreover, had professional benefits. It is indicative that in many regions the definition of 'Gyftos' (Gypsy) is synonymous with that of 'musician'. This perception challenges or even cancels the myth that 'music runs in the Roma's blood' (Keil et al. 2002: 134), created by the works of classical Gypsy Studies, ${ }^{13}$ which develop a series of certainties about the 'gypsy culture' and project a 'genetic', 'inherent' relation between the Roma and music. ${ }^{14}$

By focusing on the discussion about the aims and ambitions of the Roma musicians of Iraklia within the new circumstances, created mainly after 1922, the following observations can be made:

- The Roma are interested in prevailing in this new market and in playing a central role in the emerging political economy of music (Attali 1985), as well as in widening their musical network. This is related directly to the cultural and economic survival of their ethnic group.

- The success of this endeavour depends on the degree of their immediate adaptation to the new conditions. The transformation of the ethnic mosaic, due to the re-installation of the refugees, imposes the Roma's familiarisation with new forms of musical performances and practices, new musical genres and repertoires: Thracian, Pontic, and Gagavouzan are some of the new musical idioms which the Roma are called upon to learn and execute. Such musical idioms are added to the Vlach, Greek, and Bulgarian local (dopia) ones, as well as to the European and urban musical idioms which they dealt with prior to 1922 . In other words, they simply provide the interested parties with the appropriate music and dance, according to the occasion.

Judging from the facts, the Roma apparently adapted successfully to the new circumstances in a rather easy way, which is also due to the fact that the professional practice of music is a basic cultural ethos (habitus) of the Roma community. Their very existence in the specific field depends directly on their musical skills and 'their fingers'. Therefore, adaptation should not be conceived as an essential or magical property of the Roma culture, but as a conscious 
activity of social subjects. Bauman (1999: 95) characterises this creative form of adaptation as a par excellence 'art of the weak'. The musicians are fully aware that they are part of a multivalent system of relations and consciously follow its rules. This does not mean total subservience but a continuous process of negotiation and creative adaptation, during which the musicians manage their musical knowledge and experiences so as to improve their way of life.

Consequently, the Roma musicians have to keep themselves up to date with the musical idioms, the forms of performance, and the musical preferences of the various ethnic groups in general. However, they do not only stay informed about musical trends, but are also interested in incorporating and shaping new musical idioms, which they introduce to society before they are even comprehended. Thus, the musicians-'prophets' as agents of change renew their cultural product, making it simultaneously more attractive and reinforcing the status of their cultural identity. In a way, Attali's argument (1985: 43) on the prophetic nature of music is confirmed, since it explores an entire field of possibilities more quickly than reality can succeed in doing'.

The Roma's authoritative and timely adaptation was also favoured by another influential historical conjuncture; the efforts of the newly-established Greek nation-state to create a cultural uniformity and homogenisation ${ }^{15}$ through manipulating the ethnic traditions and cultural forms. Deviant cultural practices (dances, songs, and customs) were deemed problematic and were even prohibited. As a result, bilingual ethnic groups such as the Slavophone 'Bulgarian dopioi', the Turcophone Gagavouzans, and the Cappadocians were considered 'a problem', when using any kind of cultural expression in the mother tongue. The communities were forced to comply with and conform to the demands of the nation-state, so as to avoid suffering painful consequences. Songs were forgotten, ${ }^{16}$ dances and customs declined, and the stigmatised communities expressed themselves within the imposed and permitted national framework. So, the communities adopted many songs and dances that the nation-state promoted through the school curriculum, such as kalamatianos, tsamiko, Makedoniaxakousti, and so on. ${ }^{17}$

Based on the same logic of control and prohibition, some musical instruments were also evaluated as elements of cultural heterogeneity, and their use was considered problematic (e.g. gaida (bagpipe), Macedonian lyra (lyre), accordion). As a consequence, these instruments disappeared from the music and dance performances of the communities, with the resultant creation of a great musical void. This situation led to the prevailing of the zournas (shawm), mainly in the region of Eastern Macedonia. ${ }^{18}$ The reasons could be sought in the following:

- The shrill and piercing sound of the zournas, and generally in the remarkable dynamic of the musical duo of zournas-daouli. 
- The fact that the dynamic of these instruments precludes the simultaneous musical performance, which leads to the weakening of the songs, the lyrics of many of which were not in the Greek language. ${ }^{19}$

- The presence of the zournas-players and the economic transaction between the musician and the host reinforced the prestige of the latter (RombouLevidi 2009).

- The fact that the zournas and the daouli were not evaluated as symbols of otherness or identified with problematic cultural practices and ethnic groups.

- The agents of these musical instruments themselves. Although they were members of a stigmatised ethnic group, Roma musicians were not seen as posing a threat to the nation-state. Consequently, they were able to move freely within a large geographical area and had access to a large number of communities and ethnic groups.

- The Roma's aesthetic and artistic interpretation of regional musical cultures, which gave a new, dynamic perspective to the music and dance of Eastern Macedonia.

However, it is wrong to argue that this interactive process concerned only professional musicians, although their attempt for a personal and ethnic selfexpression constitutes a very interesting example of folk creativity.

In each case, all the above consolidated the domination of the zournas over other musical instruments and functioned to the advantage of the musicians who were called upon to fill in new cultural voids and to respond to the needs of the other stigmatised ethnic groups (Rombou-Levidi 2009).

\section{MUSIC NETWORKS AND POLITICAL ECONOMY}

After the new territorial arrangements of the Greek nation-state, it is clear that the Roma could play their music in a wide geographical area. Consequently, the musicians were involved in a broad spectrum of relations, and in a multi-ethnic situation. ${ }^{20} \mathrm{~A}$ concept that facilitates the analysis of music as a professional activity of the Roma is the 'musical network'. Kavouras (1997: 42) notes: 'The concept of the network was established in anthropology as an alternative analytical category and gradually replaced the static terms of cultural area and the dualistic schemes "tradition/modernization" or "cultural centre / cultural periphery".' The interpretational model of the music network allows the analysis of the investigated subjects and the relations and practices they develop in space and time. Thus, the dynamic character of the network allows us to describe and analyse music, as well as cultural phenomena in general, 'as "open processes" and not as "closed structures"' (Gluckman 1968: 219-237). 
Within the framework of a peculiar political economy of music, the musicians are placed at the centre of the process, since they are the music 'producers' and they maintain relations of clientele with the individuals/members of other social groups, who must pay the entry fee for participating in a music-dance event (Attali 1985). Moreover, the musicians are placed at the centre of the music performances, which reproduces a unilateral model of power. The musicians themselves determine, to a considerable degree, the procedure of the musical performance and the public is restricted to an aesthetic relation with the melodies and the context of their production. However, in the case of rituals/ ceremonies that demand a strict canonistic framework, some limits are placed on the musicians' individual interpretative practice. ${ }^{21}$

OK, we know how to play but we're not the only ones in charge [...] they'll tell us what they want, they'll tell us 'yes, play it' [...] and then we've got to play well or we're in for it. (Pelekanos, personal interview 2001)

In the model described above, the term 'power' plays a decisive role. Undoubtedly, the musicians' musical knowledge plays an important part in the power of entertainment and amusement. ${ }^{22}$ However, one should wonder about the form and the duration of this power. During the performance, the player is not defined as 'Gyftos' but as a 'musician'. Once the performance is over, the definition 'Gyftos' returns. In other words, it is a rather manipulated form of power, which is probably conceded to the musicians in order to achieve an integrated musical performance, in accordance with the local criteria (Cowan 1990).

The ephemeral character of the musicians' power is confirmed by one further fact: they themselves are not recognised as physical persons but as metaphorical personifications of their instruments (Cowan 1990). 'The daoulia ${ }^{23}$ have arrived', 'the zournades are playing', 'I've booked the instruments for the wedding' are some phrases that are indicative of this view and that, finally, gives greater status to the instruments rather than to their agents (Keil et al. 2002: 95).

The poetic representation of the instruments coexists with, or even conveys, the social depersonalisation of their agents. Concurrently, this is a choice of the clients, so that the definition of the musicians as Gyftoi is toned down during the performance. An element promoted by all manner of clients is also the musicians' place of origin. The phrase 'the musicians from Iraklia' guarantees and contributes to the successful outcome of a performance. Localism, as well as the professional ability of the musicians, has a positive influence on the definition of their cultural identity.

We play at weddings, christenings; we play at glendia, at traditional feasts (panigyria), the kourbani ${ }^{24}$ or the koudounia ${ }^{25}$ at Kali Vrysi or Nikisiani. We'll go everywhere to play, because that's our job. We play at the wrestling 
event or the giures havaci ${ }^{26}$. One hour we're here, the next hour we're somewhere else. Most of the time, we're on the move. If we stay put in the mahala and Iraklia, we'll never earn our daily bread. When other folks are on holidays, we work hard. Our fathers also did the same job under the Turkish rule. They played for our own people, for the Vlachs, for the Turks, for everyone. (Kontos, personal interview 2000).

For the Roma, music as a profession presupposes constant alacrity and mobility, which ensures their economic survival and also constitutes a dynamic and multi-level process of defining their identity. The musicians travel from place to place, offering their 'wares' to heteroclite groups and communities.

The musicians' 'journey' creates a romantic content to several Gypsy studies and is classified among the inherent traits of the Roma (Liegois 1994). Possibly, the problem stems from the fact that specific studies are influenced by structural-functionalist theories (Politou 2000:19) and are orientated towards the study of itinerant or travelling Roma. This approach, which has been largely adopted by the European Union, analyses the singularity of the Roma as a derivative of an inter-social structure and a function which 'interacts with historical circumstances; yet, nonetheless, it remains basically the same' (Politou 2000: 21).

However, the example of the Roma musicians of Iraklia is quite the opposite. The starting point of their professional journey is the mahala, the permanent place of residence, which in fact endows them with a form of locality. The musicians' journey has a purpose, a starting point and a destination: the musicians know where they come from, where they are going, what they must do and how to do it, ${ }^{27}$ where they will pass, and when and where they will return. In this context, the relation between the musicians and the places in the network of their musical performance is enhanced.

What is the musicians' relation with the places in which they play? How do the others see them and how do they see themselves? The musicians practice their profession in multi-ethnic frameworks, traversing and intersecting geographical and ethnic boundaries. Professional ability is directly dependent on their ability to transcend the cultural boundaries and to respond to whatever form of local musical demands are made (Stokes 1994: 98). So, the musicians appear as 'supra-local', 'trans-local' and, perhaps more accurately, 'trans-ethnic'.

The Roma, as music producers, cut across the geographical and symbolic boundaries between various ethnic groups, and give the music network a transethnic character, while the mahala is the place from which they set off and to which they come back. In this way, the Roma live a peculiar form of experience, by which they are able to 'beat' at the same moment 'here', and to live simultaneously the 'local', the 'ethnic', and the 'trans-ethnic'. 
Every place has its own festive days and quirks. In some places there's a programme to follow, before the zournades can play... It is a difficult job, it needs patience. You've got to know about the place you go to. The zournades know their way about. We don't get lost. Most times we come back home to Iraklia straight away after the job, no matter what time it is. (Atakas, personal interview 2000)

The Roma's professional abilities are very important for the symbolic reconstitution of the communities and the ethnic groups they visit. Music is an attractive cultural form and it is related to the cultural reproduction of the local identity as well as to frameworks and occasions of community participation (Keil \& Feld 1994: 269), such as weddings, traditional feasts, and other local ceremonies in which the members of a community participate and in which musical performance has particular gravity. The main responsibility for performances of this kind is attributed to the musicians, who, being aware of their role, shape jointly and determine together with their audience a clear framework of action.

What, however, is the status of the musicians and how is their identity defined in relation to the 'recipient community' and the place in general? Their presence in a different place is entangled in a series of paradoxes which the nature of their work elicits and enhances. Notable among these paradoxes are the following:

1. Whereas as Gypsies they would go unnoticed, as musicians they are placed at the centre of the ceremony and the music performance, for as long as it lasts. Once this is over, their identity returns to its original state. The place of the ceremony is simply a workspace for them. In each case, the merchandise (music) is of greater importance than the merchant (Roma musician). 2. Although this is a case of 'matter out of position' (Douglas 1966), 'out of place', they participate decisively in the reconstitution of the place and the formation of the identity of the other, through their capacity as musicians. In this sense, during the musical performance they occupy a transient position in localism. Their presence is not limited merely to the level of the invitee (Lemon 2000: 4), but potentially one would consider them familiar 'guests', privileged and significant visitors or 'long-term' guests (Goffman 1961).

3 . They play an active part in the musical events and ceremonies of a community but they do not consider themselves as important as the members of that community do. They contribute to the codification and formulation of the messages and meanings only to the degree that serves their professional objectives.

4. In mixed communities in particular, that is, communities in which two or more ethnic groups coexist, the musicians' role is especially important. Their music contributes to communication between the individual groups of a mixed community and, to a degree, also to social cohesion. 
5. Their relationship with the locals at the moment of performance is based on a mesh of mutual collaboration and reciprocal concessions, and is under continual negotiation (Cowan 1990). It is impossible for a ceremony to take place without the participation of the musicians.

6. They are deemed to manage and provide 'authentic' music and traditions, yet without being considered authentic themselves. They are also considered as authentic local musicians but not entirely as authentic Greeks (Keil et al. 2002).

7. They use the concept of tradition for their professional consolidation, without participating in the rhetoric on tradition. We would argue that they simply 'play' tradition, without consciously thinking about it. This enables them to move easily between tradition and modernity.

\section{MUSICSCAPES}

Other crucial questions one should ask are: What kind of music do the Roma play in the places they visit? What are its characteristics and what is its relation with the place?

It seems that the musicians extract, borrow, and 'steal' music from their local, Vlach refugees or other sources, with the aim of making financial profit. However, in no case could one reproach them for lack of artistic concern and contribution. Therefore, the known stereotype of the Roma as musical 'thieves' should be restated, since it is through a consensual and not a violent process that the ethnic groups concede the rights to the use and interpretation of their music to the 'specialists'. The principal demand in this process is that the final product satisfies the cultural criteria and the aesthetic models of its ethnic sources and that it is recognisable.

Through the elaboration of this 'borrowed' musical culture, the musicians succeed in constructing a substitute musical form which is considerably different and whose signs of the dominant group are present, though merely recognisable. The result is a musical collage of unexpected proximities, in which similarity coexists with heterogeneity.

Mostly, the music that the Roma co-formulate and manage in the end is a product of a progressive differentiation and reciprocal influence. This approach downgrades the bipolar 'authenticity/alienation' (Adorno 1941), 'folklore and fakelore' (Harker 1985), 'real and invented traditions' (Hobsbawm \& Ranger 1985 [1983]), 'pure folk culture / folklorism', which in each case merit study with regard to their ideological function. 
This differentiated music, like the musicians who play it, transcends the conventional geographical and ethnic boundaries. Being initially local, it later becomes super-local and trans-ethnic. Still, one cannot speak of authentic, pure and unadulterated musical repertoires or genres. The music of the Thracians, Vlachs, Pontics, etc., belongs to fluid and loose categories, given different meanings each time, and always dependent on the frame of reference. In an integrated nation-state, terms like 'authentic' or 'pure' refer generally to a secure historical or ethnic origin.

One should think that the terms 'repertoire' and 'genre' are inadequate for capturing this reality (Papakostas 2007; 2008), especially in cases such as European, urban, and laiki (popular) music. Through these terms, place corresponds to just one musical culture and vice-versa, while at the same time one focuses on the comparative study of musical idioms and their strict geographical distribution. The example of the musicians of Iraklia and their professional involvement with music confirms Gupta and Ferguson's (1992) view that the isomorphism between space, place, and culture is not tenable but is constructed by the nation-state and is imaged in the feeble taxonomic schemes of 'repertoire' and 'genre'. The musicians, with their continuous mobility, do not weaken localisms but enhance them with a dynamic meaning. In a strange way, with the music they provide for the places and the groups they visit, they seem to cancel, yet at the same time confirm, their geography.

Keil (Keil et al. 2002) notes that the musicians of Iraklia play many different musical genres for each ethnic group. In general, this argument is acceptable and it also reveals the particularity and the dynamism of the Roma's musical practices. However, analysing the Roma's musical performance in different places, one could argue that the musicians have formulated a pliable and fluid musical form which is composed of the sum of individual genres and which in general terms is presented considerably homogenised because, perhaps, of the abilities and range of the zournas. This form is accessible and recognisable in many places and by many different ethnic groups in the wider geographical space of Eastern Macedonia, and even further. It includes certain $s^{y r t a}{ }^{28}$, ciftetelia $^{29}$, karsilamades ${ }^{30}$, chasaposervika ${ }^{31}$, zebekika ${ }^{32}$, and table songs, familiar melodies, rhythms, and musical scales (dromoi), which transcend the boundaries of the local, the Macedonian, the Ottoman, and the Balkan, while at the same time it is in a continual dialogue with localism, without threatening it.

The process of building this musical form is based on the professional reflexes of the musicians and their dialectical relationship with the available, emergent, and promoted musicscapes. In this sense, it is a musical form that becomes a common musical meeting place, concentrating and transforming heteroclite and heterogeneous cultural and musical elements. This is a dynamic 
and dialectic field between tradition and modernity, local and non-local, Greek and non-Greek, Macedonian and non-Macedonian, Balkan and non-Balkan, folk and popular, urban and 'peasant', and last, between old and 'fashionable' (Rice 1994: 305-309). The fluidity and the constant renewal and mobility of this common musical place excludes a space of cultural purity and simplicity.

\section{SUMMARY AND FURTHER CONSIDERATIONS}

What the ethnographic example of Iraklia makes clear is that for the Roma, the term local (dopia) music is not monolithic but displays a high degree of relativity. In Roma professional logic, the concept of music is not constructed around final conclusions, but it comprises all kinds of practices, categorisation, and classification. What is enhanced in each case is the function of the music in the process of acknowledging place and identity.

The idea that music simply reflects structures has been criticised by numerous researchers (Cohen 1982; Stokes 1994), since beyond the theory of the 'reflection' of social structures, music is believed to provide the meanings via which the hierarchies of the place are negotiated, transformed (Stokes 1994), and indicative of the place and the social groups. It is simultaneously a product and a process.

The words of the music theorist Simon Frith concur with the above attitude, when he emphasises: 'Music defines a space without boundaries, a game without frontiers' (Frith 1996: 125). In this game, the musicians - either as protagonists or as extras - represent their ethnic group and test the permeability of the boundaries (spatial, ethnic, symbolic), which are continually repositioned in relation to the different reference points.

As emerges from ethno-musicological studies in the Balkans (Pettan 1996; Silverman 1996; Statelova 1998), for all its singularities the example of the Roma of Iraklia is not unique. The hearths and homes of Roma musicians with similar or even different practices are located in all the nation-states of the Balkans. In all these cases the music they play transcends the ethnic boundaries and successfully copes with the cultural plurality of the clients, through a coherent unification of their musicality.

\section{NOTES}

1 Shawm, a medieval form of the oboe.

2 According to the 2001 census, the population of Iraklia was 3,609 people and that of the wider homonymous municipality 13,173 . 
${ }^{3}$ It should also be taken into account that in northern Greece the term Gyftos refers to a permanently settled population, whereas the term Tsinganos refers to migrating or itinerant ones, which is contrary to southern Greece (see Exarchos 1996; Hunt 1999).

4 A section of a rural or urban settlement, dating to the times of the Ottoman Empire.

5 See Gupta \& Ferguson (1997: 13).

6 A Greek brigand or independence fighter.

7 Gypsies in Greek.

8 Traditional percussion, also known as tapan or davul.

9 Party or other social event that includes food, music, and dance.

${ }^{10}$ Grigoris recounts an almost identical version to Charlie Keil (Blau \& Keil \& Feld 2002: 116-117).

${ }^{11}$ According to oral testimonies of the Roma of Iraklia, the new place of settlement of the Muslim Roma was Kessani in East Thrace.

${ }^{12}$ As the zournas-player Mitsos Chintzos characteristically put it: 'The Gyftoi do what the others don't do'.

${ }^{13}$ See, e.g., Webb 1975, Clebert 1976.

${ }^{14}$ Rasmussen (1996) calls it 'innate'.

${ }^{15} \mathrm{Cf}$. Wade (2000) on the way in which the state negotiated the paradoxes of homogeneity and heterogeneity.

${ }^{16}$ E.g. bouriana and gneskasamtuk.

${ }^{17}$ Several communities, in an effort to preserve their songs and dances, as well as to avoid punishment by the mechanisms of the authorities, were led to an intermediate solution: they translated the verses of the songs and the titles of their dances into Greek. This certainly influenced the structure of the songs and dances, and the way in which they were performed. Nonetheless, this is an interesting form of negotiation and adaptation, which merits further investigation.

${ }^{18}$ It should be stressed that although the zournas was not necessarily the principal musical instrument in many communities of Eastern Macedonia, its sound was nevertheless familiar. These communities preferred their local musical instruments in the musical and dance occasions associated with the symbolic reconstitution of the community. In a few cases, they invited zournades and daoulia to play at the wedding. See also Rombou-Levidi 2009.

${ }^{19}$ A rare example of the coexistence of song and zournas is found at Nikisiani, Pangaio municipality. The singers, many of whom are excellent church cantors, sing the local songs to the accompaniment of the zournas and daouli.

${ }^{20}$ Cf. Seeger 1977.

${ }^{21}$ Even in the case of the free entry-treat, chartoura or 'stalo', as it has come to be called by the Roma musicians, the musicians have to earn it through the fullness, correctness, and aesthetic appeal of their performance.

${ }^{22}$ Cf. Foucault 1980. 
${ }^{23}$ Players of daouli.

${ }^{24}$ Traditional customs/rituals based on the idea of shared food (meat). In many cases kourbani involves music and dance events.

${ }^{25}$ Bells.

${ }^{26}$ The melody that musicians play during the traditional wrestling games.

${ }^{27}$ These are the views of Theodosiou (2003) on the Gyftoi musicians at Parakalamos, Ioannina.

${ }^{28}$ Typical Greek line dance in circle (7/8 or $\left.2 / 4\right)$.

${ }^{29}$ Belly dance.

${ }^{30}$ Dance in pairs, face to face.

${ }^{31}$ Very popular dance form in $2 / 4$.

${ }^{32}$ Improvisational dance.

\section{REFERENCES}

Adorno, Theodor W. 1941. On Popular Music. Zeitschrift für Sozialforschung, Vol. 9, No. 1, pp. 17-48. http://dx.doi.org/10.5840/zfs1941913.

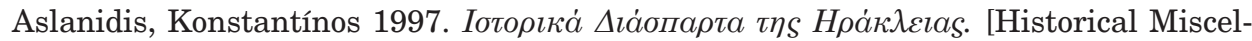
lanea of Iraklia.] Sérres: Dimotikí Vivliothíki Iráklias.

Attali, Jaques 1985. Noise: The Political Economy of Music. Minneapolis \& London: University of Minnesota Press. Available at https://monoskop.org/images/6/67/ Attali_Jacques_Noise_The_Political_Economy_of_Music.pdf, last accessed on 18 October 2018.

Barthes, Roland 1972. Mythologies. Transl. by Annette Lavers. London: Paladin.

Bauman, Zygmunt 1999. Culture as Praxis. London \& Thousand Oaks \& New Dehli: SAGE.

Bourdieu, Pierre 1977. Outline of a Theory of Practice. Cambridge: Cambridge University Press.

Clebert, Jean Paul 1967. The Gypsies. Transl. by Charles Duff. Harmondsworth: Penguin.

Cohen, Anthony P. (ed.) 1982. Belonging: Identity and Social Organization in British Rural Cultures. Manchester: Manchester University Press.

Cowan, Jane K. 1990. Dance and the Body Politic in Northern Greece. Princeton: Princeton University Press.

Douglas, Mary 1966. Purity and Danger: An Analysis of Concepts of Pollution and Taboo. London: Routledge.

Exarchos, Giorgos 1996. Avtoi عivaı or Гú $\varphi \tau$. [These Are the Gypsies.] Athens: Gavriilidis. Foucault, Michel 1980. Questions on Geography. In: C. Gordon (ed.) Power/Knowledge: Selected Interviews and Other Writings 1972-1977. New York: Pantheon Books, pp. 63-77. Available at https://monoskop.org/images/5/5d/Foucault_Michel_ Power_Knowledge_Selected_Interviews_and_Other_Writings_1972-1977.pdf, last accessed on 18 October 2018. 
Frith, Simon 1996. Music and Identity. In: Stuart Hall \& Paul du Gay (eds.) Questions of Cultural Identity. London \& Thousand Oaks \& New Delhi: SAGE, pp. 108-127.

Gluckman, Max 1968. The Utility of Equilibrium Models in the Study of Social Change. American Anthropologist, Vol. 70, No. 2, pp. 219-237. http://dx.doi.org/10.1525/ aa.1968.70.2.02a00010.

Goffman, Erving 1961. Encounters: Two Studies in the Sociology of Interaction. Indianapolis: Bobbs-Merrill.

Gupta, Akhil \& Ferguson, James 1992. Beyond "Culture": Space, Identity, and the Politics of Difference. Cultural Anthropology, Vol. 7, No. 1, pp. 6-23. http://dx.doi. org/10.1525/can.1992.7.1.02a00020.

Gupta, Akhil \& Ferguson, James (eds.) 1997. Culture, Power, Place: Explorations in Critical Anthropology. Durham: Duke University Press.

Harker, Dave 1985. Fakesong: The Manufacture of British 'Folksong', 1700 to the Present Day. Milton Keynes: Open University Press.

Hobsbawm, Eric \& Ranger, Terence 1985 [1983]. The Invention of Tradition. Cambridge: Cambridge University Press.

Hunt, Yvonne 1999. Yiftos, Tsinganos: A Note on Greek Terminology. Journal of the Gypsy Lore Society, Series 5, Vol. 9, No. 1, pp. 71-78. Available at https://babel. hathitrust.org/cgi/pt?id=inu.30000071184661;view=1up;seq=259, last accessed on 9 November 2018.

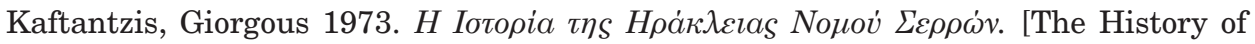
Iraklia in the Prefecture of Serres.] Iraklia Serres: Municipality of Iraklia.

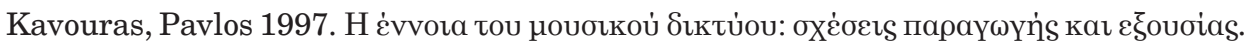

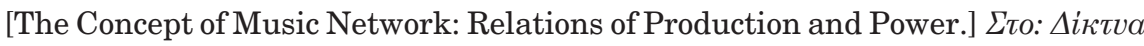

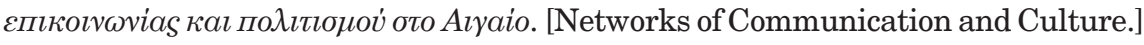
Proceedings of the 3rd Symposium for the Aegean Culture in Samos. Athens: Pnevmatiko Idrima Samou Nikolaos Dimtriou, pp. 17-36.

Keil, Charles \& Feld, Steven 1994. Music Grooves: Essays and Dialogues. Chicago: University of Chicago Press.

Keil, Charles \& Vellou Keil, Angeliki \& Blau, Dick \& Feld, Steven 2002. Bright Balkan Morning: Romani Lives and the Power of Music in Greek Macedonia. Middletown, Connecticut: Wesleyan University Press.

Lausevic, Mirjana 2007. Balkan Fascination: Creating an Alternative Music Culture in America. New York: Oxford University Press.

Lemon, Alaina 2000. Between Two Fires: Gypsy Performance and Romani Memory from Pushkin to Post-Socialism. Durham: Duke University Press.

Liegeois, Jean-Pierre 1994. Roma, Gypsies, Travellers. Strasbourg: Council of Europe. Mazower, Mark 2000. The Balkans. New York: Random House.

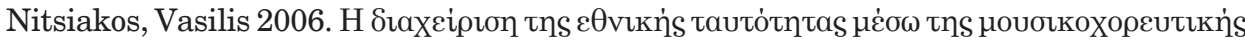

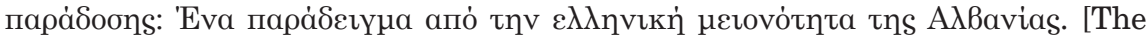
Management of National Identity through Music and Dance Tradition: An Example of the Greek Minority in Albania.] In: K. Panopoulou (ed.) Xooós kal

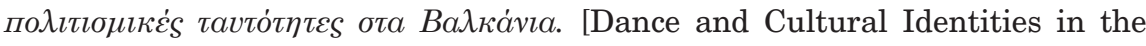
Balkans.] Proceedings of the 3rd Conference on Folk Culture. Department of Physical Education \& Sport Science, Municipality of Serres, pp. 363-372.

Okely, Judith 1983. The Traveller-Gypsies. Cambridge: Cambridge University Press. 
Olwig, Karen Fog \& Hastrup, Kirsten (eds.) 1997. Siting Culture: The Shifting Anthropological Project. New York: Routledge.

Ortner, Sherry B. 1984. Theory in Anthropology since the Sixties. Comparative Studies in Society and History, Vol. 26, No. 1, pp. 126-166. http://dx.doi.org/10.1017/ S0010417500010811.

Papakostas, Christos 2007. Repertoire: Theory vs Practice: The Greek Paradigm. In: Rethinking Practice and Theory. Proceedings of the International Symposium on Dance Research. 30th Annual Conference, Centre National de la Dance. Paris, France, 21-24 June. Riverside, CA: Society of Dance History Scholars, pp. 374-378.

Papakostas, Christos 2008. Dance and Place: The Case of a Roma Community in Northern Greece. In: Anthony Shay (ed.) Balkan Dance: Essays on Characteristics, Performance and Teaching. Jefferson, N.C.: McFarland Publishers, pp. 69-88.

Pettan, Svanibor 1996. Gypsies, Music and Politics in the Balkans: A Case Study from Kosovo. World Music, Vol. 38, No. 1, pp. 33-61. Available at https://www.jstor. org/stable/i40079773, last accessed on 18 October 2018.

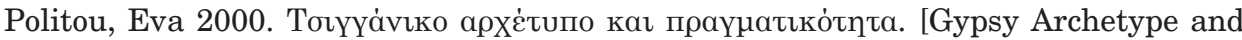

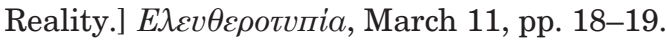

Rasmussen, Ljerka 1996. Orientalism, Rom Gypsy, and the Culture at Intersection. In: Ursula Hemetek \& Emil H. Lubej (eds.) Echo der Vielfalt / Echoes of Diversity: Traditionelle Musik von Minderheiten / ethnischen Gruppen / Traditional Music of Ethnic Groups / Minorities. Wien \& Köln \& Weimar: Böhlau, pp. 247-254.

Rice, Timothy 1994. May It Fill Your Soul: Experiencing Bulgarian Music. Chicago: The University of Chicago Press.

Rombou-Levidi, Marica 2009. Dancing beyond the 'Barre': Cultural Practices and the Processes of Identification in Eastern Macedonia, Greece. Diss. (PhD Thesis). University of Sussex, United Kingdom.

Seeger, Anthony 1977. Studies in Musicology, 1935-1975. Berkeley \& Los Angeles \& London: University of California Press.

Silverman, Carol 1996. Music and Marginality: Roma (Gypsies) of Bulgaria and Macedonia. In: M. Slobin (ed.) Retuning Culture: Musical Changes in Central and Eastern Europe. Durham: Duke University Press, pp. 231-253.

Statelova, Rosemary 1998. Sociocultural and Geopolitical Tensions Expressed through Identification with Regional Balkan Music and Its Local Variants. Music on Show: Folk traditions, Vol. 25. Finland: Tampere University Printing Service.

Stokes, Martin (ed.) 1994. Ethnicity, Identity and Music: The Musical Construction of Place. Oxford: Berg Publishers.

Theodosiou, Aspasia 2003. Authentic Performances and Ambiguous Identities: Gypsy Musicians on the Greek-Albanian Border. Diss. (PhD Thesis). University of Manchester.

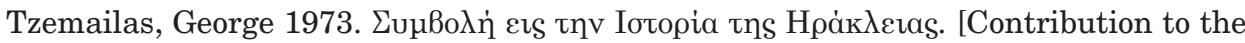
History of Irakleia.] Serraika Hronika, Vol. 6. Athens: Historical and Folklore Society of Serres-Melenikou.

Wade, Peter 2000. Music, Race, and Nation: Musica Tropical in Colombia. Chicago: The University of Chicago Press.

Webb, Godfrey 1975. Gypsies: The Secret People. London: Greenwood Press. 